\title{
Correction to: Effects of chemical sterilization of the culture media, porous membranes and luminosity on in vitro culture of Eucalyptus grandis $\times$ Eucalyptus urophylla
}

Letícia Vaz Molinari ${ }^{1}$ • Denys Matheus Santana Costa Souza ${ }^{1}$ Maria Lopes Martins Avelar ${ }^{1}$.

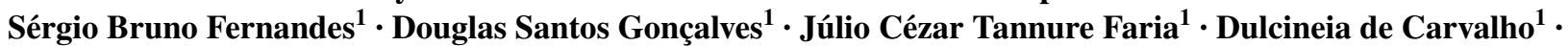
Gilvano Ebling Brondani ${ }^{1}$

Published online: 30 November 2020

(C) Northeast Forestry University 2020

Correction to: J. For. Res.

https://doi.org/10.1007/s11676-020-01240-5

In the original publication of the article, there were errors in the fig 3 and fig 6 . The corrected Figs. 3 and 6 are given below:

The original article has been corrected.

The original article can be found online at https://doi. org/10.1007/s11676-020-01240-5.

Letícia Vaz Molinari

leticia_vaz03@hotmail.com

$\triangle$ Gilvano Ebling Brondani gilvano.brondani@ufla.br

1 Department of Forestry Sciences, Federal University of Lavras, Lavras, Minas Gerais, Brazil 
Fig. 3 In vitro multiplication features recorded for different active-chlorine concentrations $(0.000 \%, 0.001 \%, 0.003 \%$, and $0.005 \%)$ and $E$. grandis Hill (ex. Maiden $) \times$ E. urophylla S.T. Blake clones (C1 and $\mathrm{C} 2$ ). a and $\mathbf{b}$ : Shoot chlorosis, $\mathbf{c}$ and $\mathbf{d}$ : Shoot oxidation, e and f: Shoot length, $\mathbf{g}$ : Number of shoots per explant. Means followed by the same letter did not differ in Tukey's test at 5\% significance level
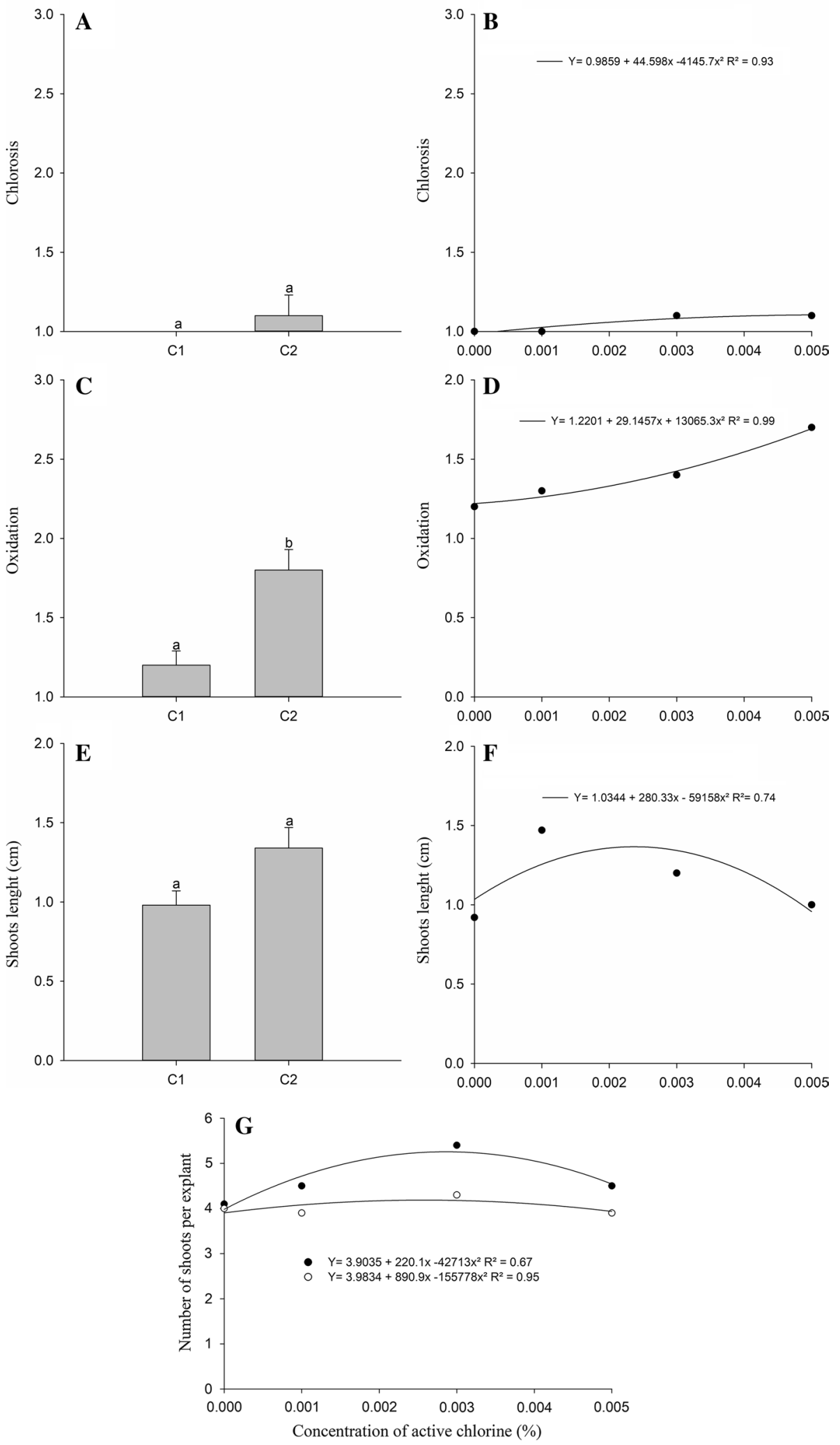
Fig. 6 In vitro adventitious rooting features observed as function of different light sources (dark and light) and sealing forms (W/M, 1/M and 3/M). a: Root length, b: Number of roots per explant, $\mathbf{c}$ and d: Root diameter, e: Rooting rate; $\mathbf{a}, \mathbf{b}$ and $\mathbf{e}$ : lowercase letters represent statistical differences among different sealing forms in the same treatment (light source); uppercase letters represent statistical differences among different light sources in the same treatment (sealing forms). Means followed by the same letter did not differ in the Tukey's test at $5 \%$ significance level
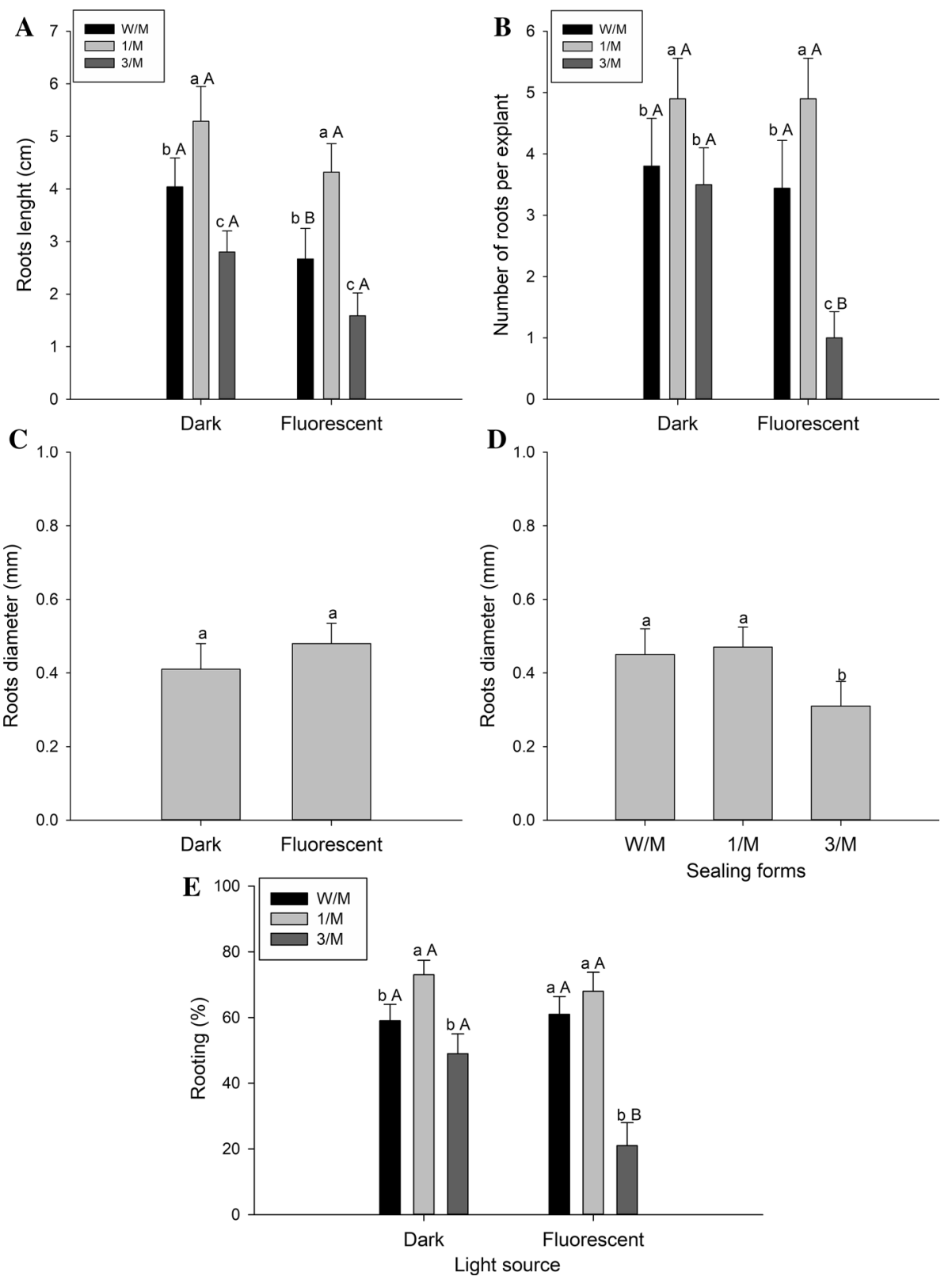

Publisher's Note Springer Nature remains neutral with regard to jurisdictional claims in published maps and institutional affiliations. 